\title{
The loss-averse competitive newsvendor model with product substitution under multiple mental accounts
}

\author{
Haifei Shou", a , Bojun $\mathrm{Gu}^{1, \mathrm{~b}}$ and Di Zhang ${ }^{1, \mathrm{c}}$ \\ ${ }^{1}$ School of Economics and Management, Zhejiang Ocean University, Zhoushan, China \\ ahaifeishou@163.com, b bojungu@163.com, ${ }^{c} 1090934304 @ q q . c o m$
}

Keywords: product substitution; multiple mental accounts; Nash equilibrium; loss aversion

Abstract. We consider a newsvendor game with two substitutable products which are sold by two retailers with loss-averse preferences under multiple mental accounts. The game theory is used to find the retailers' optimal order quantity. Given the order quantity of one retailer, there exists a unique optimal order quantity of another retailer. And it shows that substitution, degree of loss aversion, shortage cost, degree of substitution and salvage value have an impact on optimal order quantity. Further, the Nash equilibrium is unique in the loss-averse newsvendor game. There exists a threshold of loss aversion coefficient which the effect of loss aversion dominates the effect of competition. Numerical experiments are conducted to illustrate our results.

\section{Introduction}

The newsvendor model is a basic building block of stochastic inventory theory. It has been extensively studied in the past few decades. Readers who are interested in it can see Yan et al.(2011) and Khouja(1999). In this paper, we focus on the competitive newsvendor in a loss-averse scenario.

Since Kahneman and Tversky(1979) propose the prospect theory, loss-averse is apply in the newsvendor modal, such as Wang and Webster(2009).

In the competitive scenario, Liu et al.(2013) study the retailers' optimal order quantity in a competitive environment. Further, It is shown that under certain conditions, there exists a unique Nash equilibrium in the newsvendor game. And Wang(2010) extends the standard newsvendor problem based upon risk neutrality to a game setting where multiple newsvendor with loss aversion preferences are competing for inventory from a risk-neutral supplier.

However, they formulate the model by single mental account and neglect the shortage penalty cost. Obviously, it is difficult to obtain analytical results when taking the shortage penalty cost into the loss-averse competitive newsvendor model under single mental account. However, when formulated by the multiple mental accounts, the model will be more clearly to be analyzed.

Thaler(1985) proposes that decision makers have multiple mental accounts when making a decision. Then Ho et al.(2010) and Becker-Peth et al.(2013) apply it in the newsvendor model. Gu and Zhang(2017) firstly study the revenue-sharing contract for the supply chain by using multiple mental accounts. Based on multiple mental accounts, value function will evaluate accounts separately. We don't need to calculate the break-even point.

Therefore, we will formulate the competitive newsvendor model by multiple mental accounts under a loss-averse scenario and consider the shortage penalty cost in our model. The purpose of research is to find the loss-averse retailer's optimal order quantities under multiple mental accounts.

Our research shows that the loss-averse retailer's optimal order quantity is correlated with loss aversion and other parameters. There exists a unique Nash equilibrium in the newsvendor game and we analysis the joint effect of loss aversion and competition under symmetry assumption.

\section{Model formulation}

We make an assumption that there are two retailers with loss-averse preferences. Each retailer faces consumers' stochastic demand. Retailer 1 sells product 1 and retailer 2 sells product 2 . And product 1 is a substitute for product 2 . Each retailer decides their order quantity in advance. If one of the products is out of stock, the consumer might choose another product as a substitution. The unsold products will 
have salvage value while the shortage one will cause shortage cost. The piecewise-linear loss aversion utility function is as follows.

$$
U(w)=\left\{\begin{array}{ll}
w, & w>0 \\
-\lambda w, & w<0
\end{array} .\right.
$$

Notations concerned in the paper are defined as follows:

$p_{i}$ : retail price for product i $c_{i}$ : purchasing cost for product i $Q_{i}$ : order quantity for product i ;

$x_{i}$ : stochastic demand for retailer i $s_{i}$ : shortage cost for product I; $v_{i}:$ salvage value for product $\mathrm{i}$

$\alpha_{i}$ : substitution rate of product i; $\lambda_{i}$ : degree of retailer i's loss aversion ;

$f\left(x_{1}, x_{2}\right)$ : probability density function

Case 1: $x_{1} \geq Q_{1}, x_{2} \geq Q_{2}$

In case 1 , the product 1 and 2 are both out of stock. The retailer 1's profit and the expected utility are:

$\pi_{1}\left(x_{1}, x_{2}, Q_{1}, Q_{2}\right)=p_{1} Q_{1}-c_{1} Q_{1}-s_{1}\left[x_{1}-Q_{1}+\alpha_{1}\left(x_{2}-Q_{2}\right)\right]$.

$E_{1}\left[U\left(\pi_{1}\right)\right]=\int_{Q_{1}}^{+\infty} \int_{Q_{2}}^{+\infty}\left(p_{1}-c_{1}\right) Q_{1} f\left(x_{1}, x_{2}\right) d x_{2} d x_{1}-\lambda_{1} \int_{Q_{1}}^{+\infty} \int_{Q_{2}}^{+\infty} s_{1}\left[x_{1}-Q_{1}+\alpha_{1}\left(x_{2}-Q_{2}\right)\right] f\left(x_{1}, x_{2}\right) d x_{2} d x_{1}$.

Case 2: $x_{1} \geq Q_{1}, x_{2}<Q_{2}$

In case 2 , the product 1 is out of stock and the product 2 has excess inventory. Then we have:

$\pi_{1}\left(x_{1}, x_{2}, Q_{1}, Q_{2}\right)=p_{1} Q_{1}-c_{1} Q_{1}-s_{1}\left(x_{1}-Q_{1}\right)$.

$E_{2}\left[U\left(\pi_{1}\right)\right]=\int_{Q_{1}}^{+\infty} \int_{0}^{Q_{2}}\left(p_{1}-c_{1}\right) Q_{1} f\left(x_{1}, x_{2}\right) d x_{2} d x_{1}-\lambda_{1} \int_{Q_{1}}^{+\infty} \int_{0}^{Q_{2}} s_{1}\left(x_{1}-Q_{1}\right) f\left(x_{1}, x_{2}\right) d x_{2} d x_{1}$.

Case 3: $x_{1}<Q_{1}, x_{2}<Q_{2}$

In case 3 , both products have excess inventory. Then the retailer 1's profit and expected utility are:

$\pi_{1}\left(x_{1}, x_{2}, Q_{1}, Q_{2}\right)=p_{1} x_{1}-c_{1} Q_{1}-v_{1}\left(Q_{1}-x_{1}\right)=\left(p_{1}-c_{1}\right) x_{1}-\left(c_{1}-v_{1}\right)\left(Q_{1}-x_{1}\right)$.

$E_{3}\left[U\left(\pi_{1}\right)\right]=\int_{0}^{Q_{1}} \int_{0}^{Q_{2}}\left(p_{1}-c_{1}\right) x_{1} f\left(x_{1}, x_{2}\right) d x_{2} d x_{1}-\lambda_{1} \int_{0}^{Q_{1}} \int_{0}^{Q_{2}}\left(c_{1}-v_{1}\right)\left(Q_{1}-x_{1}\right) f\left(x_{1}, x_{2}\right) d x_{2} d x_{1}$.

Case 4: $x_{1}<Q_{1}, x_{2}>Q_{2}+\left(Q_{1}-x_{1}\right) / \alpha_{1}$

In this case, the product 1 has the excess inventory but can't satisfy the demand derived from substitution while the product 2 is out of stock. Then we have

$\pi_{1}\left(x_{1}, x_{2}, Q_{1}, Q_{2}\right)=p_{1} Q_{1}-c_{1} Q_{1}-s_{1}\left[\alpha_{1}\left(x_{2}-Q_{2}\right)-\left(Q_{1}-x_{1}\right)\right]$.

(8)

$$
\begin{aligned}
& E_{4}\left[U\left(\pi_{1}\right)\right]=\int_{0}^{Q_{1}} \int_{Q_{2}+\left(Q_{1}-x_{1}\right) / \alpha_{1}}^{+\infty}\left(p_{1}-c_{1}\right) Q_{1} f\left(x_{1}, x_{2}\right) d x_{2} d x_{1} \\
& -\lambda_{1} \int_{0}^{Q_{1}} \int_{Q_{2}+\left(Q_{1}-x_{1}\right) / \alpha_{1}}^{+\infty} s_{1}\left[\alpha_{1}\left(x_{2}-Q_{2}\right)-\left(Q_{1}-x_{1}\right)\right] f\left(x_{1}, x_{2}\right) d x_{2} d x_{1}
\end{aligned}
$$

Case 5: $x_{1}<Q_{1}, Q_{2} \leq x_{2} \leq Q_{2}+\left(Q_{1}-x_{1}\right) / \alpha_{1}$

Here, the product 1 has excess inventory which can satisfy the demand derived from substitution. The product 2 is out of stock.

$\pi_{1}\left(x_{1}, x_{2}, Q_{1}, Q_{2}\right)=\left(p_{1}-c_{1}\right)\left[x_{1}+\alpha_{1}\left(x_{2}-Q_{2}\right)\right]-\left(c_{1}-v_{1}\right)\left[Q_{1}-x_{1}-\alpha_{1}\left(x_{2}-Q_{2}\right)\right]$.

(10) 


$$
\begin{aligned}
& E_{5}\left[U\left(\pi_{1}\right)\right]=\int_{0}^{Q_{1}} \int_{Q_{2}}^{Q_{2}+\left(Q_{1}-x_{1}\right) / \alpha_{1}}\left(p_{1}-c_{1}\right)\left[x_{1}+\alpha_{1}\left(x_{2}-Q_{2}\right)\right] f\left(x_{1}, x_{2}\right) d x_{2} d x_{1} \\
& -\lambda_{1} \int_{0}^{Q_{1}} \int_{Q_{2}}^{Q_{2}+\left(Q_{1}-x_{1}\right) / \alpha_{1}}\left(c_{1}-v_{1}\right)\left[Q_{1}-x_{1}-\alpha_{1}\left(x_{2}-Q_{2}\right)\right] f\left(x_{1}, x_{2}\right) d x_{2} d x_{1}
\end{aligned} .
$$

Thus, we can combine five cases and express the retailer 1's total expected utility as

$$
\begin{aligned}
& E\left[U\left(\pi_{1}\left(x_{1}, x_{2}, Q_{1}, Q_{2}\right)\right)\right] \\
& =\int_{Q_{1}}^{+\infty} \int_{0}^{+\infty}\left(p_{1}-c_{1}\right) Q_{1} f\left(x_{1}, x_{2}\right) d x_{2} d x_{1}+\int_{0}^{Q_{1}} \int_{0}^{Q_{2}}\left(p_{1}-c_{1}\right) x_{1} f\left(x_{1}, x_{2}\right) d x_{2} d x_{1} \\
& +\int_{0}^{Q_{1}} \int_{Q_{2}+\left(Q_{1}-x_{1}\right) / \alpha_{1}}^{+\infty}\left(p_{1}-c_{1}\right) Q_{1} f\left(x_{1}, x_{2}\right) d x_{2} d x_{1}+\int_{0}^{Q_{1}} \int_{Q_{2}}^{Q_{2}+\left(Q_{1}-x_{1}\right) / \alpha_{1}}\left(p_{1}-c_{1}\right)\left[x_{1}+\alpha_{1}\left(x_{2}-Q_{2}\right)\right] f\left(x_{1}, x_{2}\right) d x_{2} d x_{1} \\
& -\lambda \int_{Q_{1}}^{+\infty} \int_{Q_{2}}^{+\infty} s_{1}\left[x_{1}-Q_{1}+\alpha_{1}\left(x_{2}-Q_{2}\right)\right] f\left(x_{1}, x_{2}\right) d x_{2} d x_{1}-\lambda_{1} \int_{Q_{1}}^{+\infty} \int_{0}^{Q_{2}} s_{1}\left(x_{1}-Q_{1}\right) f\left(x_{1}, x_{2}\right) d x_{2} d x_{1} \\
& -\lambda \int_{0}^{Q_{1}} \int_{0}^{Q_{2}}\left(c_{1}-v_{1}\right)\left(Q_{1}-x_{1}\right) f\left(x_{1}, x_{2}\right) d x_{2} d x_{1}-\lambda_{1} \int_{0}^{Q_{1}} \int_{Q_{2}+\left(Q_{1}-x_{1}\right) / \alpha_{1}}^{+\infty} s_{1}\left[\alpha_{1}\left(x_{2}-Q_{2}\right)-\left(Q_{1}-x_{1}\right)\right] f\left(x_{1}, x_{2}\right) d x_{2} d x_{1} \\
& -\lambda_{1} \int_{0}^{Q_{1}} \int_{Q_{2}}^{Q_{2}+\left(Q_{1}-x_{1}\right) / \alpha_{1}}\left(c_{1}-v_{1}\right)\left[Q_{1}-x_{1}-\alpha_{1}\left(x_{2}-Q_{2}\right)\right] f\left(x_{1}, x_{2}\right) d x_{2} d x_{1}
\end{aligned}
$$

Proposition 1. Given any $Q_{2}$, the retailer 1 's expected utility function $E\left[U\left(\pi_{1}\left(x_{1}, x_{2}, Q_{1}, Q_{2}\right)\right)\right]$ is concave in $Q_{1}$. Thus a unique optimal order quantity $Q_{1} *\left(Q_{2}\right)$ exists which can be characterized in the following first-order condition:

$$
\begin{aligned}
& \int_{Q_{1}^{*}\left(Q_{2}\right)}^{+\infty} \int_{0}^{+\infty}\left(p_{1}-c_{1}\right) f\left(x_{1}, x_{2}\right) d x_{2} d x_{1}+\int_{0}^{Q_{1}^{*}\left(Q_{2}\right)} \int_{Q_{2}+\frac{Q_{1}^{*}\left(Q_{2}\right)-x_{1}}{\alpha_{1}}}^{+\infty}\left(p_{1}-c_{1}\right) f\left(x_{1}, x_{2}\right) d x_{2} d x_{1}+\lambda_{1} \int_{0}^{Q_{1}^{*}\left(Q_{2}\right)} \int_{Q_{2}+\frac{Q_{1}^{*}}{\alpha_{1}}\left(Q_{2}\right)-x_{1}}^{+\infty} s_{1} f\left(x_{1}, x_{2}\right) d x_{2} d x_{1} \\
& +\lambda_{1} \int_{Q_{1}^{*}\left(Q_{2}\right)}^{+\infty} \int_{0}^{+\infty} s_{1} f\left(x_{1}, x_{2}\right) d x_{2} d x_{1}-\lambda_{1} \int_{0}^{Q_{1}^{*}\left(Q_{2}\right)} \int_{0}^{Q_{2}+\frac{Q_{1}^{*}\left(Q_{2}\right)-x_{1}}{\alpha_{1}}}\left(c_{1}-v_{1}\right) f\left(x_{1}, x_{2}\right) d x_{2} d x_{1}=0
\end{aligned}
$$

Similarly, Given any $Q_{1}$, the retailer 2's expected utility function $E\left[U\left(\pi_{2}\left(x_{1}, x_{2}, Q_{1}, Q_{2}\right)\right)\right]$ is concave in $Q_{2}$. Differ to the Liu et al.(2013), we study the loss-averse newsvendor game with product substitution based on multiple mental accounting model. We also consider shortage penalty cost which is mentioned in Liu et al.(2013). Proposition 1 shows that $E\left[U\left(\pi_{1}\left(x_{1}, x_{2}, Q_{1}, Q_{2}\right)\right)\right]$ is still concave in $Q_{1}$ when taking the shortage penalty cost into the model.

Corollary 1. The optimal order quantity $Q_{1}{ }^{*}$ is decreasing in $Q_{2}$.

In other words, the more retailer 2's order quantity, the less optimal order quantity of retailer 1. Moreover, the result is same as the Liu et al.(2013) without shortage penalty cost. So whether considering the shortage cost or not makes no difference to the result.

Corollary 2. Given any $Q_{2}$, then $Q_{1} *$ is decreasing in $\lambda_{1}$ when $\frac{\partial R\left(Q_{1}{ }^{*}, Q_{2}, \lambda_{1}, \alpha_{1}\right)}{\partial \lambda_{1}}<0 ; Q_{1} *$ is increasing $\lambda_{1}$ when $\frac{\partial R\left(Q_{1}^{*}, Q_{2}, \lambda_{1}, \alpha_{1}\right)}{\partial \lambda_{1}}>0$.

Corollary 2 shows that the sensitivity of $\lambda$ to $Q_{1}{ }^{*}$ is depending on $R\left(Q_{1}^{*}, Q_{2}, \lambda_{1}, \alpha_{1}\right)$. When $\partial R\left(Q_{1}^{*}, Q_{2}, \lambda_{1}, \alpha_{1}\right) / \partial \lambda_{1}<0$, the risk-neutral retailer will order more than the loss-averse retailer, and the higher lever of loss aversion lead to less inventory. While $\partial R\left(Q_{1}^{*}, Q_{2}, \lambda_{1}, \alpha_{1}\right) / \partial \lambda_{1}>0$, the result is on the contrary. Therefore, the impact of $\lambda_{1}$ to the retailer 1's optimal order quantity is different to the found in the Liu et al.(2013). 
Corollary 3. Given any $Q_{2}$, then $Q_{1}$ * is increasing in $\alpha_{1}$.

It follows from corollary 3 that the higher degree of substitution 1, the more fraction of demand for product 2 which will switch to the product 1 . In other words, retailer 1's order quantity will be increased in order to meet the higher effective demand.

Corollary 4. Given any $Q_{2}$, then $Q_{1} *$ is increasing in $\mathrm{s}_{1}$.

This corollary indicates the change of shortage cost makes much effect on retailer's decision. When the shortage cost per unit of product 1 is more, the retailer 1 will increase his order quantity.

Corollary 5. Given any $Q_{2}$, then $Q_{1} *$ is increasing in $\mathrm{v}_{1}$.

It implies that the higher salvage value per unit of product 1 , the more order quantity to be satisfied.

Proposition 2. A Nash equilibrium exists in the loss-averse newsvendor game with product substitution and the Nash equilibrium is characterized by the following conditions:

$$
\begin{aligned}
& \int_{Q_{1}}^{+\infty} \int_{0}^{+\infty}\left(p_{1}-c_{1}\right) f\left(x_{1}, x_{2}\right) d x_{2} d x_{1}+\int_{0}^{Q_{1}} \int_{Q_{2}+\left(Q_{1}-x_{1}\right) / \alpha_{1}}^{+\infty}\left(p_{1}-c_{1}\right) f\left(x_{1}, x_{2}\right) d x_{2} d x_{1}+\lambda_{1} \int_{0}^{Q_{1}} \int_{Q_{2}+\left(Q_{1}-x_{1}\right) / \alpha_{1}}^{+\infty} s_{1} f\left(x_{1}, x_{2}\right) d x_{2} d x_{1} \\
& +\lambda_{1} \int_{Q_{1}}^{+\infty} \int_{0}^{+\infty} s_{1} f\left(x_{1}, x_{2}\right) d x_{2} d x_{1}-\lambda_{1} \int_{0}^{Q_{1}} \int_{0}^{Q_{2}+\left(Q_{1}-x_{1}\right) / \alpha_{1}}\left(c_{1}-v_{1}\right) f\left(x_{1}, x_{2}\right) d x_{2} d x_{1}=0 \\
& \int_{Q_{2}}^{+\infty} \int_{0}^{+\infty}\left(p_{2}-c_{2}\right) f\left(x_{1}, x_{2}\right) d x_{1} d x_{2}+\int_{0}^{Q_{2}} \int_{Q_{1}+\left(Q_{2}-x_{2}\right) / \alpha_{2}}^{+\infty}\left(p_{2}-c_{2}\right) f\left(x_{1}, x_{2}\right) d x_{1} d x_{2}+\lambda_{2} \int_{0}^{Q_{2}} \int_{Q_{1}+\left(Q_{2}-x_{2}\right) / \alpha_{2}}^{+\infty} s_{2} f\left(x_{1}, x_{2}\right) d x_{1} d x_{2} \\
& +\lambda_{2} \int_{Q_{2}}^{+\infty} \int_{0}^{+\infty} s_{2} f\left(x_{1}, x_{2}\right) d x_{1} d x_{2}-\lambda_{2} \int_{0}^{Q_{2}} \int_{0}^{Q_{1}+\left(Q_{2}-x_{2}\right) / \alpha_{2}}\left(c_{2}-v_{2}\right) f\left(x_{1}, x_{2}\right) d x_{1} d x_{2}=0
\end{aligned}
$$

We can obtain $\left|d Q_{1}^{*} / d Q_{2}\right|<1$ and $\left|d Q_{2}^{*} / d Q_{1}\right|<1$ in any case from the proof of proposition 2 . Therefore the Nash equilibrium is unique. The result is different from Liu et al.(2013). In Liu et al.(2013), the Nash equilibrium is unique only if the conditions $\alpha_{1} \leq\left(c_{1}-v_{1}\right) /\left(p_{1}-v_{1}\right)$ and $\alpha_{2} \leq\left(c_{2}-v_{2}\right) /\left(p_{2}-v_{2}\right)$ are satisfied.

Assumption 1. We consider that each retailer's loss aversion degree is $\lambda$. And two products have the same selling price $p$, purchasing cost $c$, shortage cost $s$ and salvage value $v$. We also make the following assumption that the demands of two products are independent and identically distributed random variables with probability density function $\mathrm{g}(\mathrm{x})$.

Then denote the equilibrium order quantity by $Q^{*}$ and let

$$
K(Q, \lambda)=(p-c+\lambda s)\left[1+(\alpha / 2) G(Q)^{2}-(\alpha / 2) G(Q+Q / \alpha)^{2}\right]+\lambda(c-v)(\alpha / 2)\left[G(Q)^{2}-G(Q+Q / \alpha)^{2}\right]
$$

Then we can follow from $(15)$ that $K\left(Q^{*}, \lambda\right)=0$.

Corollary 6. Under Assumption 1, the retailers' equilibrium order quantity are equivalent. They are decreasing in $\lambda$ when $\partial R(Q, \lambda, \alpha) / \partial \lambda<0$ and increasing in $\lambda$ when $\partial R(Q, \lambda, \alpha) / \partial \lambda<0$. And they are increasing in $\alpha$.

In the Liu(2013), they compare the optimal order quantity of each loss-averse retailer under competition with that of each product under centralization. In Netessine and Rudi(2003), it shows that with the case of centralized inventory management, competition leads to inventory up for each risk-neutral retailer. Here, we call it competition effect. Similarly, $Q^{c}$ is defined as the optimal order quantity under centralization and

$$
\lambda_{0}=-\frac{(p-c)\left[1+(\alpha / 2) G\left(Q^{c}\right)^{2}-(\alpha / 2) G\left(Q^{c}+Q^{c} / \alpha\right)^{2}\right]}{s+[(\alpha s / 2)+(c-v) \alpha / 2]\left[G\left(Q^{c}\right)^{2}-G\left(Q^{c}+Q^{c} / \alpha\right)^{2}\right]} .
$$

Proposition 3. When $\partial R\left(Q_{1}{ }^{*}, Q_{2}, \lambda_{1}, \alpha_{1}\right) / \partial \lambda_{1}<0$, if $\lambda>\lambda_{0}$, then $Q^{*}<Q^{\mathrm{c}}$, otherwise $Q^{*} \geq Q^{\mathrm{c}}$. And when $\partial R\left(Q_{1}^{*}, Q_{2}, \lambda_{1}, \alpha_{1}\right) / \partial \lambda_{1}>0, Q^{*} \geq Q^{\mathrm{c}}$. 
When $\partial R\left(Q_{1}^{*}, Q_{2}, \lambda_{1}, \alpha_{1}\right) / \partial \lambda_{1}<0$, the loss aversion effect can decrease each retailer's order quantity while the competition effect can increase each retailer's order quantity. In Corollary 6 , there exists $\lambda_{0}$ which the effect of loss aversion is greater than the effect of competition. Hence, it is similar to Proposition 3 in Liu (2013) which states the total inventory level of a decentralized supply chain is lower than that of centralized supply chain. However, when $\partial R\left(Q_{1}{ }^{*}, Q_{2}, \lambda_{1}, \alpha_{1}\right) / \partial \lambda_{1}>0$, both the loss aversion effect and competition effect increase retailer's order quantity.

\section{Conclusions}

This paper is based on a multiple newsboy problem with shortage cost and two substitutable products. It shows that there exists a unique optimal order quantity of retailer 2 when given an order quantity of retailer 1. And the order quantities are decreasing in the loss aversion coefficient and substitution rate. They are increasing in shortage cost of product and salvage value of product. Further, we characterize the unique Nash equilibrium in any cases. Then we obtain, under centralized inventory management, a threshold of loss aversion coefficient, above which the effect of loss aversion is greater than the effect of competition. In order to illustrate the effect of loss aversion and product substitution.

\section{Acknowledgements}

This paper was partly supported by: (i) National Natural Science Foundation of Zhjiang Province [grant number LY18G010016]; (ii) Zhoushan Science and Technology Project [grant number 2017C41018]; (iii)The Open Foundation from Marine Sciences in the Most Important Subjects of Zhejiang [grant number 20130212]; (iv) The Open Foundation from Fishery Sciences in the First-Class Subjects of Zhejiang [grant number 20160023] and (v) technology innovation activity plan of college students in Zhejiang province science and the new seedling talent plan implementation office.

\section{References}

[1]. Yan Q. The newsvendor problem: Review and directions for future research. European Journal of Operational Research. Vol. 213 (2011). p. 361-374.

[2]. Moutaz Khouja. The single-period (news-vendor) problem: literature review and suggestions for future research. Omega-International Journal of Management Science. Vol. 27 (1999). p. 537-553.

[3]. X. W. Charles, S. Webster. Channel Coordination for a Supply Chain with a Risk-Neutral Manufacturer and a Loss-Averse Retailer. Decision Sciences. Vol. 38 (2007). p. 361-389.

[4]. Charles X. Wang. The loss-averse newsvendor game. International journal of Production Economics. Vol. 124 (2010). p. 448-452.

[5]. Liu W, Song S, Wu C. Impact of loss aversion on the newsvendor game with product substitution. International Journal of Production Economics. Vol. 141 (2013). p. 352-359.

[6]. Thaler, Richard H. Mental accounting and consumer choice. Marketing Science. Vol. 4 (1985). p. 199-214.

[7]. Ho T, Lim N, Cui T H. Reference-Dependence in Multi-Location Newsvendor Models: A Structural Analysis. Management Science. Vol. 56 (2009). p. 1891-1910.

[8]. Beckerpeth M, Katok E, Thonemann U W. Designing Buyback Contracts for Irrational but Predictable Newsvendors. Management Science. Vol. 59 (2013). p. 1800-1816.

[9]. Charles X. Wang, Scott Webster. The loss-averse newsvendor problem. Omega. Vol. 37 (2009). p. 93-105.

[10]. Wang C X, Webster S. Channel Coordination for a Supply Chain with a Risk-Neutral Manufacturer and a Loss-Averse Retailer. Decision Sciences. Vol. 38 (2007). p. 361-389.

[11]. Bojun $\mathrm{Gu}$, Xiang Zhang. Risk neutral supplier and loss aversion retailer supply chain coordination based on revenue sharing contract. Systems Engineering. Vol. 25 (2016). p. 67-74. 